Print ISSN: 2735 - 4121 Online ISSN : 2735-413X

\title{
Prevalence of Hepatitis B and CViruses among Health Care Workers at Governmental Hemodialysis Units
}

\author{
1Mona Metwally Hussein, 2Mona EmadEldien Hussein \&3Samar El- HoseinyAbd El-Raouf \\ 1BSc, Faculty of Nursing, Cairo University,Infection control practitioner at Dakahllia Medical \\ Affairs, 2Lecturer of CommunityHealth Nursing, 3Professor of Community Health Nursing, Faculty of \\ Nursing, Mansoura University, Egypt
}

\begin{abstract}
Egypt has one of the highest prevalence rates of hepatitis $\mathrm{C}$ virus (HCV) in the world. Occupational exposure to $\mathrm{HBV}$ and $\mathrm{HCV}$ is a well-recognized risk for health care workers (HCWs). The current study conducted to determine the prevalence of HBV and $\mathrm{HCV}$ among HCWs in governmental hemodialysis units in Daqahlyagovernance (DG). Cross-sectional design was utilized to carry out this study. This study was conducted at 33 governmental hemodialysis units. The total number of the study participants were 1043 HCWs. Structured interviews were run to assess socio-demographic, and occupational characteristic of HCWs; their health history, and laboratory investigations were carried outto estimate the prevalence of HBV and HCV among themwhich were firstly for HCV (hepatitis $\mathrm{C}$ virus antibody 3rd generation);secondly for HBV (HBsAg, and hepatitis B surface antigen).Results indicated that $46.8 \%$ of HCWs aged 30 to less than 40 years, $45.6 \%$ of HCWs were university education, $94.7 \%$ of $\mathrm{HCWs}$ received $\mathrm{HBV}$ vaccination, finally prevalence of $\mathrm{HCV}$ was $5.4 \%$, while prevalence of $\mathrm{HBV}$ was $0.48 \%$. the researcher could be concluded that: prevalence of both HBV and HCV among heath care workers at governmental hemodialysis units in Dakahlya governorate is very low; with the highest one for HCV than HBV. Finally, this study recommended that: Regular screening for HBV and $\mathrm{HCV}$ infection status among HCWs specially in hemodialysis units should be performed. Key words: Blood borne infection, Health care workers, Hepatitis B virus,Hepatitis C virus, Infection control
\end{abstract}




\section{Introduction}

Prevalence of Hepatitis B and C Viruses among Health Care Workers at Governmental Hemodialysis Units Hepatitis B virus (HBV) and hepatitis $\mathrm{C}$ virus (HCV) are among the main causes of liver-associated diseases, including liver cirrhosis and hepatocellular carcinoma(Schillie, et al., 2018; Kapadia \& Marks, 2018). Both viruses are major global public healthproblemswarranting high

priorityefforts for prevention, control and treatment. Approximately two billion individuals worldwide have been infected by HBV, and between 350 and 400 million individuals havechronicHBVinfection, while an estimated 200 million people (i.e., 3.3\% of the world's population) are chronically infectedby HCV worldwide (Elzouki et al., 2014).

A majority of countries in the Middle East show an intermediate or high endemicity of HBV infection, which clearly poses a serious public health problem in the region. Egypt has one of the highest prevalence rates of hepatitis $\mathrm{C}$ virus (HCV) in the world, mostly with genotype 4 that is highly associated with severe fibrosis (Raad, et al., 2018).

The World Health Organization (WHO) estimated that 1 in 3 people in the world have been infected by either HBV or HCV and 1.3 million people have died as a result of this disease in 2015. It has been reported that 2 billion people have been infected with $\mathrm{HBV}$; approximately 185 million of those people are infected with HCV (Jefferies et al., 2018).

The modes of transmission of these two blood-borne viruses in developing countries include perinatal transmission or household contact, sexual contact, shared needles in intravenous drug abusers and contaminated blood or organ transplants are responsible for their transmission in developed countries. But, screening tests as well as vaccination for HBV have dramatically reduced the risk of transmission worldwide (Yasin, et al., 2019).

Occupational exposure to HBV and $\mathrm{HCV}$ is a well-recognized risk for health care workers (HCWs). The assessment of the risk of transmission to $\mathrm{HCWs}$ requires information derived from various sources including the place of HCW hospital work, the working period, the type of occupation, and the rate of exposure to patients' blood and blood products. The rates of transmission of $\mathrm{HBV}$ and $\mathrm{HCV}$ to HCWs are also influenced by the prevalence of $\mathrm{HBV}$ and $\mathrm{HCV}$ infection in the general population (Deuffic-Burban et al., 2011).

In developing countries, the prevalence of $\mathrm{HBV}$ and $\mathrm{HCV}$ among HCWs is high, while the vaccination status among HCWs and its relationship with occupational factors are not well documented (Gaziano, et al., 2015).

Many researches were conducted to estimate the prevalence of $\mathrm{HBV}$ and $\mathrm{HCV}$ infections among hemodialysis patients. The full extent of $\mathrm{HCV}$ transmission in dialysis units is unknown, outbreaks continue to occur. Full compliance to standard/specific infection control procedures and routine serologic screening for $\mathrm{HCV}$ antibody play a pivotal role for preventing the transmission of $\mathrm{HCV}$ within hemodialysis units (Fabrizi, \&Messa, 2015).

Public health nurses have been working as community advocates, 
educators, and providers of critical public health services. Public health nurses are the largest group of providers of public health services. They provide a variety of essential services to the communities in which they work. The primary role of the public health nurse is to work within the community to support population health and deliver preventive health care services (Kulbok\& Thatcher, 2012 \&Tanhope\& Lancaster, 2011).

Because the information regarding transmission of blood-borne viruses in $\mathrm{HCWs}$ is very limited in Egypt, the current study conducted to determine the prevalence of $\mathrm{HBV}$ and HCV among HCWs in Governmental Hemodialysis Units in Dakahlia governance. A further aim of this study was to analyze how the risk of these infections are affected by the type of occupation and the working period as well as the vaccination status among this high risk group.

\section{Aim of the Study:}

The aim of the study was to estimate the prevalence of hepatitis B and $C$ viruses among health care workers in Dakahlia governmental hemodialysis units.

\section{Method}

\section{Study Design}

A cross sectional study design was used to carry out this research.

\section{Settings}

This study was conducted at 33 (All) governmental hemodialysis units, affiliated to Ministry of Health and Population in Dakhllia governorate.

\section{Participants}

The total numbers of the study participants were 1043 health care workers from total target of 1480, divided into 56 physicians, 454 diploma nurses, 376 high-qualified nurses, 17 lab technicians, 79 machine technicians, and 66 housekeepers.

\section{Sampling}

I. Sampling technique and sample size of Dkahlia governmental hemodialysis units

The following steps were conducted to clarify distribution of Dkahlia governmental hemodialysis units:

- Dkahlia governmental hemodialysis units were 33, classified into; 30 governmental, two-health insurance, and one El Amana Specialized Hospitals.

II. Sampling technique and sample size of health care workers (HCWs) providing health care at hemodialysis units

Stratified random sample technique was used. The following steps were conducted to select the study sample:

- Average number of HCWs on duty during the study period in governmental hemodialysis units, affiliated to Ministry of Health and Population in DG was 1480.

- The calculated sample size of this study was $1043 \mathrm{HCWs}$, using the following formula.

$$
\mathbf{N}=\mathbf{Z}^{2} \mathbf{P}(\mathbf{1}-\mathbf{P})
$$

Where

$\mathbf{Z}=1.96$ for $95 \%$ confidence level.

$\mathbf{p}=$ expected prevalence of satisfaction $(0.50)$.

$\mathbf{d}=$ precision (Margin of error) $=0.05$

- The sample size was increased to 1043 HCWs to compensate for drop outs or any failures with incomplete data.

- A simple random sampling technique, taking into consideration proportion allocation was used to select 1043 out of $1480 \mathrm{HCWs}$ to estimate the prevalence $\mathrm{f} \mathrm{HBV}$ and 


\author{
HCV infection among them. \\ Study tools \\ After reviewing, the relevant \\ literatures four tools were developed by \\ the researcher used to collect data. \\ First tool: Structured interview to \\ assess socio-demographic \\ characteristic \\ The socio-demographic
} characteristic of health care workers, which were age, sex, residence, and marital status.

Second tool: Structured interview to assess occupational characteristic

It was concerned with assessment of occupationalcharacteristic of health care workers including: level of education, occupation, years of experience at different departments, and, hemodialysis units, working shifts, training courses, and availability of disinfectants, personal protective equipment, and infection control policy at hemodialysis units.

Third tool: Structured interview to assess health history

The tool was constructed from three parts as the following:

\section{Part I: Previous health history}

This part concerned with history of chronic diseases, blood transfusion, surgeries, dental procedures, prodromal symptoms, liver diseases. Previous incidence of needle sticks injuries, and exposure to splash of blood or its derivatives.

\section{Part II: Family history}

This part concerned with presence of a relative having $\mathrm{HBV}$ and/or $\mathrm{HCV}$ infections, residence with those relatives at the same house hold, sharing the personal items with $\mathrm{HBV} / \mathrm{HCV}$ relatives, and having $\mathrm{HBV}$ vaccination.

\section{Part III: Current health history:}

This part concerned with smoking habits among HCWs, last virology investigations of $\mathrm{HBV} / \mathrm{HCV}$ performed to HCWs, Knowledge about source of infections, and state of vaccinations.

Fourth tool: Laboratory investigations Laboratory investigations were carried out to detect old and new cases from health care workers with $\mathrm{HCV}$ and HBV through these types of tests for $\mathrm{HCV}$ (hepatitis $\mathrm{C}$ virus antibody $3^{\text {rd }}$ generation) and for $\mathrm{HBV}$ ( $\mathrm{HBsAg}$, and hepatitis B surface antigen).

\section{Phases of the study}

\section{Phase I: Administrative process}

An official letter was issued from the Faculty of Nursing, Mansoura University to the director of Dakhllia Medical Affairs to permit the researcher to carry out the study.

Phase II: Development of study tools

- Tools were developed by the researcher after reviewing the related literature.

- Face and content validity. According to Litwin, (1995); Maruish, (2011); Miller, (2010); Polit and Beck, (2006) and Tavakol and Dennick, (2011) face validity is established when an individual (and or researcher) who is an expert on the research subject reviewing the questionnaire (instrument) concludes that it measures the characteristic or trait of interest. Content validity pertains to the degree to which the instrument fully assesses or measures the construct of interest. Study tools were tested for appropriateness and have relevant items, by five experts in department of Community Health Nursing, Faculty of Nursing, and Mansoura University.

- A pilot study. It was carried out on $10 \%$ (104) HCWs of the study 
sample who assigned conveniently, and excluded from the main study sample accordingly.

Phase II: Operational phase

\section{Stage 1: Data collection}

- Data collection for the first four months (from September to December) three times/week. The researcher visited governmental hemodialysis units during (Sunday, Monday and Tuesday); from 9 am to $12 \mathrm{pm}$, each visit ranged between 60 to 120 minutes.

- Data collected by structured interview questionnaire to assess socio-demographic and occupational characteristic, health history, and laboratory investigations of HCWs.

Stage 2: Blood sample collection and laboratory investigations

A blood sample (5-10ml) was extracted by the researcher for each $\mathrm{HCW}$, labeled and sent immediately to the local laboratory, in the same hospital in which the HCWs are working, where it was centrifuged and the sera were stored at $-20^{\circ} \mathrm{c}$ until transported to the central laboratories at Dakahlia Medical Affairs. Samples were tested for (hepatitis $\mathrm{C}$ virus antibody $3^{\text {rd }}$ generation) for HBV (HBsAg, and hepatitis B surface antigen).

\section{Stage 3: ethical consideration}

- An approval was obtained from Research Ethics Committee, Faculty of Nursing, and Mansoura University.

- An informed consent was obtained from the health care workers. The researcher introduces herself to HCWs and a simple explanation about the aim of the study.

- Health care workers informed that they have the right to withdraw at any time from the study without giving any reason.
- Health care workers informed that the researcher would cover all cost of laboratory investigations.

- They assured that their participation in the study was voluntary and that collected data treated confidentially and would be only used for the purpose of the study.

\section{Stage 4: Statistical analysis}

- Statistical analysis was performed with SPSS version 22 (SPSS Inc, Chicago, IL, USA) Chi-square was used to compare the differences between various categorical data frequencies and the student.

\section{Results}

Table (1):showedthat $46.8 \%$ of HCWs aged 30 to less than 40 years. Related to sex, residence, and marital status $91.3 \%, 77.1 \%$, and $91.7 \%$ of HCWs were males, resident at rural areas, and married respectively.

Table (2): illustratedthat $45.6 \%$ of HCWs were university education. Technical nurses represented $43.3 \%$ of the studied health care workers. In relation to shift; $46.0 \%, 50.9 \%, 66.3 \%$, and $71.1 \%$ of the studied health care workers; working at morning and evening shifts, for 1-2 shifts, for 2-8 hours, dealing with 1-9 cases respectively. Finally, $36.7 \%$ of $\mathrm{HCWs}$ had 5 to less than 10 years of experience in dialysis.

Table (3):displayed that $53.4 \%$ of HCWs started their work in dialysis units. Workers in Dialysis department represented $53.4 \%$ of HCWs. Regarding the periods of work, $71.5 \%$ of HCWs had $<5$ years of experience, while $22.0 \%$ of them had experience from 5 to $<10$ years. Finally, $68 \%$ of HCWs worked 28 hours per shift. 
Table (4): reveals that $80.9 \%$ and $63.8 \%$ of HCWs had 1-5 training courses from less than 5 years.

Table (5):revealed that solutions of hand disinfection and choler for floor disinfection were available in $96.9 \%$ and $84.3 \%$ of hemodialysis units respectively. In terms of availability of personal protective equipment, gloves and masks were available by $96.9 \%$ and $66.6 \%$ respectively. Finally, 90.9\%, $78.7 \%$, and $45.4 \%$ of hemodialysis units expendgloves, gowns, and masks respectively.

Table (6):showed that infection prevention, and control policy was present in $90.9 \%$ of hemodialysis units. Training on infection prevention, and control policy was carried out in $84.8 \%$ of hemodialysis units. Compliance to infection prevention, and control policy was reported by $66.6 \%$ of hemodialysis units. In relation to reporting of needle stick injuries, $45.4 \%$ of hemodialysis units reported to infection prevention, and control team.

Table (7):illustrated that $28.5 \%$ of HCWs exposed to NSI, $73.06 \%$ of these NSI were superficial. In relation to number of NSI $69.36 \%$ of HCWs exposed to 2-5 times since a week. Cleaning site of NSI by chlorine, hand washing, and squeezing the site of NSI were performed by $53.2 \%, 50.1$, and $38.0 \%$ of HCWs, respectively. Infection control team fulfill post exposure sheet and identified the vaccination status in $68.0 \%$ and $60.2 \%$ of $\mathrm{HCWs}$

Table (8):indicatedthat $21.5 \%$ of HCWs exposed to blood splash with frequency of 1-5 times representing $17.8 \%$, and since a week representing $16.3 \%$. In relation to action performed, $13.8 \%$ of HCWs wash site exposed to splashes, and $12.8 \%$ of them informed the infection control team. In relation to the amount and type of splashes, $19.3 \%$ of HCWs exposed to blood with little amount.

Table (9):displayed that $3.0 \%$ of HCWs had relatives infected with HBV, $64.5 \%$ of them were first-degree, and $1.3 \%$ of them had HBV vaccination. In relation to relatives with $\mathrm{HCV}$ infection, $14.5 \%$ of HCWs had relatives with HCV infection, $81.5 \%$ of them were firstdegree relatives. Nobody of HCWs shared the personal items of the $\mathrm{HBV} / \mathrm{HCV}$ infected relatives.

Table (10):revealed that $83.1 \%$ of HCWs did not perform HBV investigation. In relation of the results of the investigation, $99.4 \%$ of $\mathrm{HCWs}$ were negative HBV. The table showed that $83.1 \%$ of $\mathrm{HCWs}$ did not perform $\mathrm{HCV}$ investigation. In relation of the results of the investigation, $96.5 \%$ of $\mathrm{HCWs}$ were negative HBV. Regarding regularity of virology investigation in the hospital, $83.1 \%$ of HCWs reported that no regular analysis made in the hospital.

Table (11):showed that $57.5 \%$, $50.6 \%$, and $41.8 \%$ of $\mathrm{HCWs}$ thought that viral infection occurs because of their exposing to infected patients, improper sterilization of instruments, and improper disinfection of surfaces, respectively. HBV vaccine was available in hemodialysis units, belonged to $91.8 \%$ of HCWs. Concerning with receiving HBV vaccination during work at DU $94.7 \%$ of $\mathrm{HCW}$ s received $\mathrm{HBV}$ vaccination. No one of HCWs investigated the response titer of the vaccination.

Table (12):indicated that prevalence of $\mathrm{HCV}$ was $5.4 \%$, while prevalence of HBV was $0.48 \%$. 
Prevalence of Hepatitis B and CViruses etc...

\begin{tabular}{|c|c|c|}
\hline Items & No & $\%$ \\
\hline \multicolumn{3}{|l|}{ Age (years) } \\
\hline $20-$ & 436 & 41.8 \\
\hline $30-$ & 488 & 46.8 \\
\hline $40-$ & 85 & 8.1 \\
\hline $50-60$ & 34 & 3.3 \\
\hline \multicolumn{3}{|l|}{ Mean $31.79 \pm(7.01)$} \\
\hline \multicolumn{3}{|l|}{ Sex } \\
\hline $\begin{array}{ll}\text { Males } \\
\text { Females }\end{array}$ & $\begin{array}{c}952 \\
91\end{array}$ & $\begin{array}{l}91.3 \\
8.7\end{array}$ \\
\hline \multicolumn{3}{|l|}{ Residence } \\
\hline $\begin{array}{ll}\text { Rural } \\
\text { Urban }\end{array}$ & $\begin{array}{l}804 \\
239\end{array}$ & $\begin{array}{l}77.1 \\
22.9\end{array}$ \\
\hline \multicolumn{3}{|l|}{ Marital status } \\
\hline $\begin{array}{ll}\text { Married } \\
\text { Single } \\
\text { Divorced } \\
\text { Widow } \\
\end{array}$ & $\begin{array}{c}956 \\
44 \\
31 \\
12 \\
\end{array}$ & $\begin{array}{l}91.7 \\
4.2 \\
3.0 \\
1.2 \\
\end{array}$ \\
\hline
\end{tabular}

Table 2.Current occupational characteristics of HCWs $(n=1043$ (

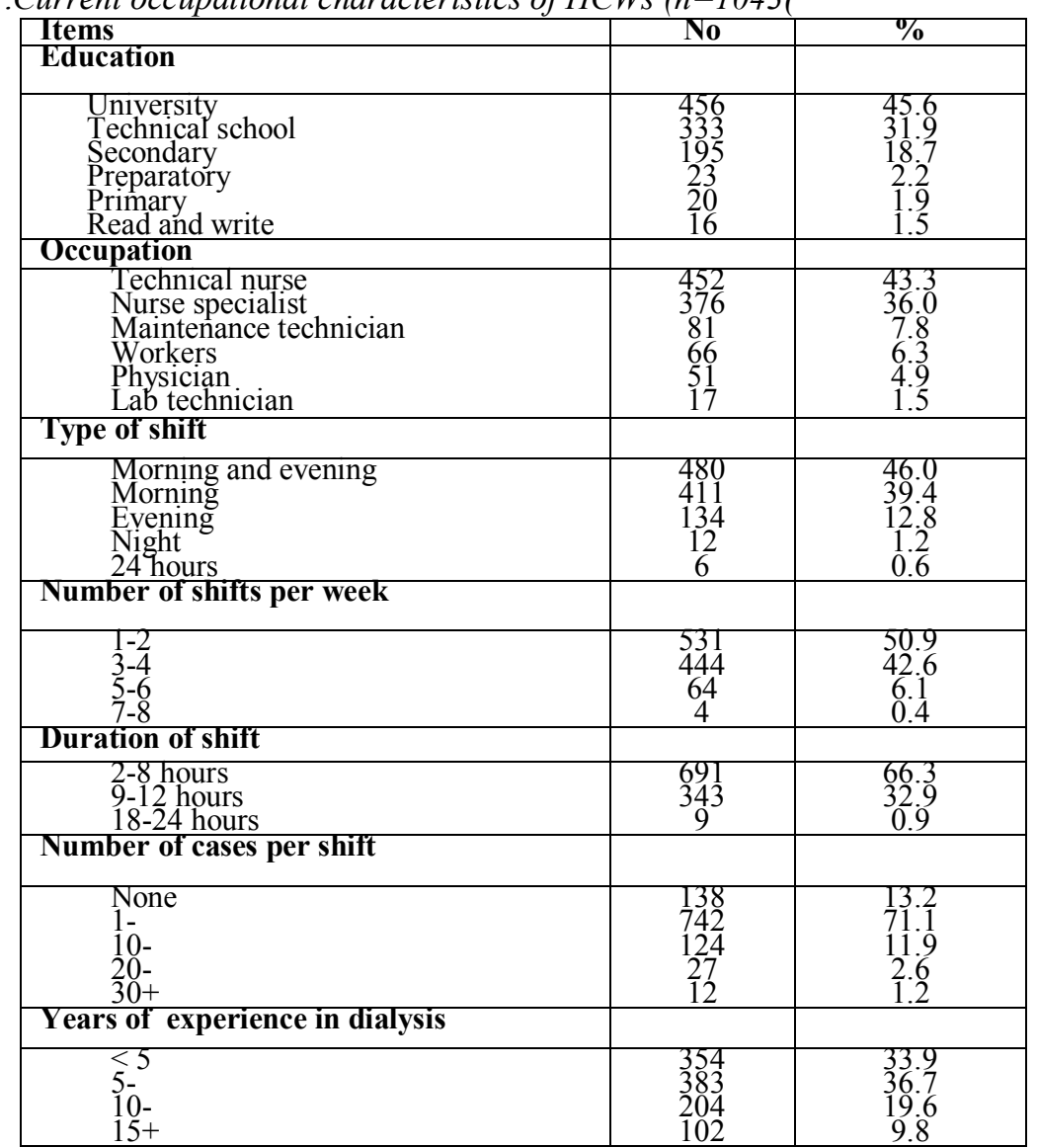


1Mona Metwally Hussein et. al

Table 3 .Previous occupational characteristics of HCWS $(n=1043($

\begin{tabular}{|l|c|c|}
\hline Items & No & $\%$ \\
\hline Place of work & & \\
\hline Start in dialysis & 557 & 53.4 \\
Other departments & 486 & 46.6 \\
\hline Departments & & \\
\hline Dialysis & 557 & 53.4 \\
Obstetric & 26 & 2.5 \\
Surgery & 63 & 3.0 \\
Neonatal ICU & 59 & 6.0 \\
Internal Medicine & 72 & 5.7 \\
ICUs & 130 & 12.5 \\
Emergency & 20 & 1.9 \\
Operiatrics & 33 & 3.2 \\
Otherting room & 52 & 4.9 \\
\hline Periods of work & & \\
\hline < 5 years & 750 & 71.5 \\
10 & 230 & 22.0 \\
15+ & 14 & 5.2 \\
\hline Duration of shift & & 1.3 \\
\hline 2-8 hours & 712 & \\
9-12 hours & 320 & 68.2 \\
>12 hours & & 30.5 \\
\hline
\end{tabular}

Table 4. Training courses for HCWs $(n=1043)$

\begin{tabular}{|c|c|c|}
\hline \multicolumn{2}{|c|}{ No } & $\%$ \\
\hline Items & \multicolumn{2}{|c|}{} \\
\hline \multicolumn{2}{|c|}{ Number of training courses } & 7.2 \\
\hline None & 75 & 80.9 \\
$1-5$ & 844 & 12.1 \\
$6-10$ & 117 & 0.7 \\
$>10$ & 7 & 7.2 \\
\hline \multicolumn{2}{|c|}{ Duration since last training course (years) } \\
\hline None & 75 & 6.1 \\
\hline$>1$ & 64 & 63.8 \\
\hline$<5$ & 665 & 22.9 \\
\hline $5-10$ & 239 & \\
\hline
\end{tabular}

Table 5 .Availability of disinfectants and personal protective equipment at hemodialysis units ( $n \mathrm{r}=$ hemodialysis units(

\begin{tabular}{|c|c|c|}
\hline Items & No & $\%$ \\
\hline \multicolumn{3}{|l|}{ Availability of disinfectants } \\
\hline Solutions of hand disinfection & 32 & 96.9 \\
\hline Choler for floor disinfection & 28 & 84.8 \\
\hline Soap for hand washing & 18 & 54.5 \\
\hline Ethylene alcohol 60-90\% & 15 & 45.4 \\
\hline Betadine $10.0 \%$ for patients & 1 & 3.0 \\
\hline \multicolumn{3}{|c|}{ Availability of personal protective equipment } \\
\hline Gloves & 32 & 96.9 \\
\hline Masks & 22 & 66.6 \\
\hline Gwen & 14 & 42.4 \\
\hline Face shield & 8 & 24.2 \\
\hline Eye shield & 5 & 15.1 \\
\hline Head protective & 3 & 9.0 \\
\hline Nothings & 1 & 3.0 \\
\hline \multicolumn{3}{|c|}{ Personal protective equipment expendsduring work } \\
\hline Gloves & 30 & 90.9 \\
\hline Gwen & 26 & 78.7 \\
\hline Masks & 15 & 45.4 \\
\hline Eye shield & 3 & 9.0 \\
\hline Nothings & 2 & 6.0 \\
\hline Head protective & 1 & 3.0 \\
\hline Face shield & 1 & 3.0 \\
\hline
\end{tabular}


Prevalence of Hepatitis B and CViruses etc...

Table6 .Infection prevention, andcontrol policy in hemodialysis units $(n(\mathrm{rr}=$

\begin{tabular}{|c|c|c|}
\hline Items & No & $\%$ \\
\hline Infection prevention, andcontrol policy & 30 & 90.9 \\
\hline Training on infection prevention, and control policy & 28 & 84.8 \\
\hline Compliance to infection prevention, and control policy & 22 & 66.6 \\
\hline Needle stick injuries policy & 26 & 78.7 \\
\hline Training on reporting incidence of needle stick injuries & 14 & 42.4 \\
\hline Policies of preventing blood borne diseases & 24 & 72.7 \\
\hline Training on prevention from blood borne diseases & 17 & 51.5 \\
\hline \multicolumn{3}{|l|}{ Notification of NSI or exposure to blood or its derivatives } \\
\hline Infection prevention, and control team & 15 & 45.4 \\
\hline Infection prevention, and control team and supervisors & 7 & 21.2 \\
\hline Supervisors & 5 & 15.1 \\
\hline Occupational safety personnel & 4 & 12.1 \\
\hline Go to physician & 3 & 6.0 \\
\hline Others* & 1 & 3.0 \\
\hline
\end{tabular}

Others* Emergency services, Infection control and supervisor and occupational safety personnel, Do not know and No one

Table 7 .Incidence of needle stick injuries among HCWs $(n=1043$ (

\begin{tabular}{|l|c|c|}
\hline Items & No & \% \\
\hline Depth of NSI in last year(297) & 297 & 28.5 \\
\hline Superficial & 208 & 73.06 \\
\hline Penetrate the skin & 81 & 22.90 \\
\hline Deep & 3 & 3.70 \\
\hline Not sure & 5 & 0.34 \\
\hline Number of NSI (297) & & \\
\hline Once & 54 & 18.18 \\
\hline $2-5$ & 206 & 69.36 \\
\hline 6-9 & 31 & 10.44 \\
\hline 10+ & 6 & 2.02 \\
\hline Duration since last NSI (297) & & \\
\hline One week & 217 & 73.06 \\
\hline 2 weeks & 68 & 22.90 \\
\hline 15-30 days & 11 & 3.70 \\
\hline More than one month & 1 & 0.34 \\
\hline Actions done just after NSI & 158 & \\
\hline Clean site Of NSI by chlorine & 149 & 53.20 \\
\hline Hand washing & 113 & 30.17 \\
\hline Squeeze the site of NSI & 82 & 27.05 \\
\hline Apply alcohol after cleaning & 20 & 6.73 \\
\hline Wash by betadine & 26 & 8.75 \\
\hline Investigation for the source patients & 17 & 5.72 \\
\hline Do Nothing & 12 & 4.04 \\
\hline Wash by betadine and notify infection control & & \\
\hline Actions taken by infection control team & 202 & 68.01 \\
\hline Fulfilling post exposure sheet & 179 & 60.27 \\
\hline Find vaccination state and complete doses & 54 & 18.18 \\
\hline Investigations for the injected persons & 34 & 11.45 \\
\hline No thing & 24 & 8.08 \\
\hline Investigations for the source & & \\
\hline \hline
\end{tabular}


1Mona Metwally Hussein et. al

Table 8 .Exposure to splash of blood or its derivatives among HCWs ( $n=1043$ (

\begin{tabular}{|l|c|c|}
\hline Items & No & $\mathbf{\%}$ \\
\hline Exposure to blood splash & 224 & 21.5 \\
\hline Frequency & & \\
\hline $1-5$ times & 186 & 17.8 \\
\hline 6-10 times & 38 & 3.6 \\
\hline Duration since last exposure to blood splash & & \\
\hline One week & 170 & 16.3 \\
\hline 2 weeks & 52 & 5.0 \\
\hline 15-30 days & 2 & 0.2 \\
\hline Actions done just after splash (224) & & \\
\hline Washing site exposed to splashes & 144 & 13.8 \\
\hline Notify infection control and safety team & 134 & 12.8 \\
\hline Recognize source patient & 43 & 4.1 \\
\hline No thing & 12 & 1.2 \\
\hline Substances were exposed to & & \\
\hline Blood & 201 & 19.3 \\
\hline Blood derivatives & 17 & 1.6 \\
\hline Obvious bloody secretions & 31 & 3.0 \\
\hline Water used to remove blood or its derivatives & 8 & 0.8 \\
\hline Non obvious bloody secretions & 2 & 0.2 \\
\hline The amount & 198 & 19.0 \\
\hline Little & 26 & 2.5 \\
\hline Heavy & & \\
\hline
\end{tabular}

Table 9. Families' health history of HCWs $(n=1043)$

\begin{tabular}{|l|c|c|}
\hline Items & No & \% \\
\hline Presence of a relative having HBV infection & 31 & 3.0 \\
\hline First degree & 20 & 64.5 \\
\hline Second or more & 11 & 35.5 \\
\hline Residence at the same house hold & 12 & 1.1 \\
\hline Sharing the personal items with HBV relatives & 31 & 3.0 \\
\hline No participation & 31 & 3.0 \\
\hline Having HBV vaccination & 14 & 1.3 \\
\hline Presence of a relative having HCV infection & 151 & 14.5 \\
\hline First degree & 123 & 81.5 \\
\hline Second or more & 28 & 18.5 \\
\hline Residence at the same house & 64 & 42.4 \\
\hline Residence at other house & 87 & 57.6 \\
\hline Sharing personal items with HCV relatives & & \\
\hline No participation & 147 & 14.1 \\
\hline
\end{tabular}


Prevalence of Hepatitis B and CViruses etc...

\begin{tabular}{|c|c|c|}
\hline $\begin{array}{l}\text { Table10.Virological investigationscarried out by } \\
\text { (TaminSandob,Al frdos, MnietElnasr,Tlkha,Btra,Atmeda) }\end{array}$ & $\begin{array}{l}\text { hemodialysis } \\
(n=176)\end{array}$ & units to \\
\hline Items & No & $\%$ \\
\hline \multicolumn{3}{|l|}{ Duration since last HBV investigations (1043) } \\
\hline Not done & 867 & 83.1 \\
\hline $10-$ & 61 & 5.8 \\
\hline $5-$ & 51 & 4.8 \\
\hline $15+$ & 47 & 4.5 \\
\hline$<5$ & 17 & 1.6 \\
\hline \multicolumn{3}{|l|}{ Results of HBV (176) } \\
\hline Negative & 175 & 99.4 \\
\hline Positive & 1 & 0.5 \\
\hline \multicolumn{3}{|l|}{ Duration since last HCV investigations (1043) } \\
\hline$<5$ & 17 & 1.6 \\
\hline $5-$ & 51 & 4.8 \\
\hline 10- & 61 & 5.8 \\
\hline $15+$ & 47 & 4.5 \\
\hline Not done & 867 & 83,1 \\
\hline \multicolumn{3}{|l|}{ Results of HCV(176) } \\
\hline Negative & 170 & 96.5 \\
\hline Positive & 6 & 3.4 \\
\hline \multicolumn{3}{|l|}{ Regularity of virology investigation in hospitals (1043) } \\
\hline No regularvirology investigation & 867 & 83,1 \\
\hline Every 6 months & 176 & 16,8 \\
\hline
\end{tabular}

Table 11 .Knowledge about source of infections and state of vaccinations among HCWs $(n=1043$ (

\begin{tabular}{|l|c|c|}
\hline \multicolumn{1}{|c|}{ Items } & No & \\
\hline Source of infections & & \\
\hline Infected patients & 600 & 57.5 \\
\hline Improper sterilization of instruments & 528 & 50.6 \\
\hline Improper disinfection of surfaces & 436 & 41.8 \\
\hline Do not know & 110 & 10.5 \\
\hline Availability of HBV vaccination at hemodialysis units & 957 & 91.8 \\
\hline Receiving HBV vaccination during work at DU & 988 & 94.7 \\
\hline TotalHCWs received first dose & 990 & 94,9 \\
\hline None & 53 & 5.1 \\
\hline Total HCWsreceived second dose & 973 & 93,3 \\
\hline None & 70 & 6.7 \\
\hline Total HCWsreceived third dose & 953 & 91,4 \\
\hline None & 90 & 8.6 \\
\hline Measuring antibody titer to know vaccine response & 0 & 0.0 \\
\hline
\end{tabular}


1Mona Metwally Hussein et. al

Table 12. Prevalence of HCV and HBV among HCWs $(n=1043)$

\begin{tabular}{|c|c|c|}
\hline Items & No & $\%$ \\
\hline HCV & 56 & 5.4 \\
\hline HBV & 5 & 0.48 \\
\hline
\end{tabular} $\begin{gathered}\text { quarter of themhas middle level of } \\
\text { Discussion } \\
\text { Blood-borne infections have been }\end{gathered}$

recognized as an occupational hazard for nearly 50 years. Current treatment for hepatitis $B$ virus (HBV) and hepatitis $C$ virus $(\mathrm{HCV})$ is very expensive for individuals in developing countries and cannot clear infection after it progresses to the chronic stage. Thus, early screenings of people who are at higher risk like healthcare workers and vaccination and awareness creation on standard precautions (SP) to prevent transmission are mandatory (Hebo et al., 2019).

There are about 130 million persons having hepatitis $\mathrm{C}$ infection worldwide. Its prevalence varies from region to region. The highest prevalence $(15-20 \%)$ has been found in Egypt. Hepatitis B on the other hand, has been found to infect about 350 million people globally. Like hepatitis $\mathrm{C}$, the prevalence of hepatitis B also varies from low to high in different parts of the world (Sani et al., 2018).

Concerning educational level of studied HCWs, results show that almost half of HCWs are university educated; one third of them graduated from technical schools, and almost one quarter of them haslower degrees of education. The obtained resultscome in agreement with Aldohyan et al., (2019) in Saudi Arabia who findthat almost half of respondent healthcare workers has college degree or higherwhile the remaining has lower educational degrees. In contrast, Awimero et al., (2017) in Nigeria find that more than two thirds of HCWs are highly educated, and one
Regarding occupationof enrolled HCWs, majority of them arenurses, while remaining of them are physicians, lab technicians, maintenance technician, this result supported by Aldohyan et al., (2019) in KSA who report that three quarters of HCWs are nurses.

In terms of studied HCWs' experience, results indicate that almost one third of HCWs in the hemodialysis units has $<5$ years of experience, second one third has 5-10 years of experience, while the remaining has $>10$ years of experience. In the same line with a study conducted about Needle-stick injury among health care workers in hemodialysis units in Nigeria by, Amira and Awobusuyi, (2014) report that almost half of HCWs has 1-5 years of experience in hemodialysis units, more than one-fifth has 6-10 years of experience, and $22.5 \%$ of them have $>10$ years of experience. While Shahdadi and Rahnama, (2018) report that HCWs have 4.7 years average experience in hemodialysis department

The current results indicate that most of studied HCWs attend at least 1-5 training courses since less than 5 years. This result is in the line with Iliyasu et al., (2016) who report the hospital hold regular infection control training in a Tertiary Referral Center in NorthWestern Nigeria. Alrubaiee et al., (2017) in private hospitals in Sana'a City, Yemen, find that less than 5 years $(64.7 \%)$ of employment in the hospitals of HCWs attain high training course about nosocomial infections and 78.8\% of them attain training on infection 
control. In addition, Chuc et al., (2018) report that Ministry of Health popularizes and updates documents for continued training in hospital infection control. In contrast, Desta et al., (2018) report that three quarters of HCWs in Debre Markos referral hospital, Northwest Ethiopia, have not taken any training about infection prevention.

Concerning the presence of disinfectants and personal protective equipment at hemodialysis units, current study's results show that they are available, and expend. These results agree with Khamis et al., (2018 b), who find that availability of antiseptic supplies is good in the majority of all hemodialysis units in Menoufia. On the other hand, these findings contradict with a study of Khamis et al., (2018) aim to assess safety measures in hemodialysis (HD) units in DakhliaGovernorate; the researchers find that the medical team does not commit enough to wash hands despite the availability of disinfectants. Moreover, there is no commitment with regard to the use of personal protective equipment.

As well in contrast to our findings Le et al., (2019)conduct a study in a large central hospital in Vietnam, as the researchers report that $\mathrm{HCWs}$ find barriers within the hospital made it difficult for them to adhere to the hand hygiene guidelines, which include a lack of hand hygiene supplies, inconvenient placement of the supplies, patient overcrowding, work overload and pressure, skin reactions to hand sanitizers, lack of awareness, old habits of not washing hands, and forgetfulness.

Regarding infection prevention, and control policy and its application in studied hemodialysis units, the results displayed that majority of hemodialysis units have policy of infection prevention, and control, and they mostly applied the adopted policy. In the same line of our findings Mahfouz et al., (2014), in Southwestern Saudi Arabia, indicate that compliance of infection control policy among WHCs, in all departments in the hospital, particularly hand hygiene is significantly increased after a training course. In a recent study for Brooks et al., (2020) the authors suggest that research from previous infectious diseases suggests a major cause of nosocomial transmission is healthcare professionals' poor compliance with recommended personal protective behaviors.

In contrast, Yassin et al., (2018) reported that in HD units in Kasr AlAiny Hospitals, no document infection control policies and procedures are present, both units didn't follow any immunization policy for $\mathrm{HBV}$ and isolation precautions weren't implement properly. No Focus Group Discussion (FGD) isconduct with the nursing staff in HD units; it is found that the main obstacle in compliance with infection control practices is absence of welldefined infection control team.

In relation to notification of needle stick injuries, almost half ofthe studied hemodialysis units notify the infection prevention, and control team, which come in agreement with Ottino et al., (2019) who find that half of the total NSI in Italy occur in the patient's room, and nurses are involved in most of the cases, and half of NSI occur during the disposal of the venous sampling device. Also, Mahajan and Gupta, (2019) indicate that disadvantage with the current reporting system is that it most often records only cases with an important exposure, thus leading to under-reporting of sharp injury cases with wide variation in the prevalence of 
NSI among HCWs world widely, HCWs need to be familiar with immediate management both for themselves if they become injured and for assisting injured colleagues.

Çiçek-Şentürk et al., (2019), in Ankara-Turkey, indicated that NSIs are more commonly report by trainee nurses $(44.5 \%)$, followed by nurses $(22.2 \%)$, cleaning staff (19.8\%), and doctors (9\%). The rate of post exposure interventions is $92.6 \%$ NSI rates also show that the number of applications with NSIs increased over the years.

Regarding performing cleaning site of NSI and hand washing, in the current study, almost half of studied HCWs perform cleaning site of NSI and hand washing, less than three quarters of them exposed to NSI during last week and more than two thirds of them perform incidence notification (report sheet). Performing investigation for injured person or for patient, who is the source of injuring, represents one tenth total of NSI incidences. These results come in consistent with Voideet al., (2012) who find that $9.7 \%$ of HCWs ina Swiss University Hospital have sustained at least one NSSI during the preceding twelve months. In a study in a German Tertiary Care Hospital, Himmelreich et al., (2013) find that per 100 patient bed $29.2 \%$ of HCWs expose to NSI with almost one NSI per working day.

In contrast to our findings study of Foda et al., (2018)that conduct in Alexandria University Faculty of Medicine, report that majority of NSIs occur because of non-effective or successful practices of disposable injection equipment, and waste containers. High prevalence of NSSIs is report $(61.3 \%)$, mostly during handling suture needles $(50.8 \%)$.
In relation to exposure to blood splash, the current findings indicate that almost one quarter of the studied HCWs expose to blood splash with frequency of 1-5 times since a week, in the consistent with Butsashvili et al., (2012) who find that almost half of HCWs from seven medical institutions in five cities in Georgia as they report exposing to nosocomial risk events, including accidental needle stick injury (45\%), cuts with contaminated instruments $(38 \%)$ and blood splashes (46\%). Also, in a study of Samargandy et al., (2016) which carry out in King Abdulaziz University Hospital, Jeddah, Kingdom of Saudi Arabia, majority (78.5\%) of $\mathrm{HCWs}$ expose to blood or blood products spills during their morning shifts.

In relation to action done, more than half of HCWs wash the exposed site, and half of them inform the infection prevention, and controlteam. According to Samargandy et al., (2016), which is conducted in KSA, majority of HCWs expose to blood and blood splashes, wash the site of spilling and investigating the viral status of patient source of contamination, while only of them perform complete follow-up of viral status, Thirty four individuals receive a dose of $\mathrm{HBV}$ vaccine empirically as a primary or a booster dose after exposure.

Results obtained in the current study show that one and six out of 129 of studied HCWs have positive laboratory results of $\mathrm{HBV}$, and $\mathrm{HCV}$ respectively, most of them report no regularvirology investigation, and $\mathrm{HBV}$ vaccination is present in HD units and most of studied HCWs are vaccinated in their units, these results come in agreement with Tufon et al., (2019) who find that All HCWs, in the Southwest Region of Cameroon, knew about HBV infection and half of 
them have taken the vaccine. Probable evidence of past infection (positive for anti-HBc only) is recorded in few (7.1\%) of HCWs.

Yuan et al., (2019) report that majority of HCWs in China receive at least one dose of the hepatitis B vaccination and $60 \%$ complete $\geq 3$ doses of the hepatitis B vaccination.

While El-Melligy et al., (2016) conduct a study in the HCWs at Ahmed Maher Teaching Hospital, one of the hospitals of the General Organization of Teaching Hospitals and Institutes in Cairo, Egypt. The authors report that majority of the HCWs receive full $\mathrm{HBV}$ vaccination; $73.6 \%$ of them are vaccinated in the last 5 years. Lack of protective hepatitis $B$ surface antibody (HBs-Ab) titer isfound in $27.2 \%$ of the participants. $\mathrm{HCV}-\mathrm{Ab}$ is positive in $6.14 \%$ HCWs. In the study of De Schryver et al., (2020) report that HBV vaccination is mandatory for medical and nursing staff in 10 European countries.

Our results indicate that prevalence of $\mathrm{HCV}$ is identified in few numbers of studied HCWs, which come in agreement with Bernieh, (2015) who report the prevalence of $\mathrm{HCV}$ infection is $4.1 \%$, also, Westermann et al., (2015) who findthat prevalence of $\mathrm{HCV}$ infection among HCWs is $3.8-6.0 \%$. As well as, Tavoschi et al., (2019) find that prevalence of $\mathrm{HBV}$ in European Union/European Economic Area (EU/EEA) country $0.6-2.2 \%$, and For $\mathrm{HCV}$ the prevalence is $0.8-6.4$.

Sani et al., (2018) report that The prevalence of $\mathrm{HBV}$ among $\mathrm{HCWs}$ inDutse Metropolis Jigawa State, Nigeria, is 19 out of 100 and that of $\mathrm{HCV}$ is 5 out of 100 where in both cases, higher prevalence is observed among female nurses. The study reveal that nurses are at greater risk of contracting
HBV and HCV due to their frequent contact with patients.

While Shao et al., (2018) find that prevalence of HBV among health care workersin northern Tanzania is $5.7 \%$ which is similar to their national prevalence. Also, AbdAlla et al., (2017) findthat the overall prevalence of $\mathrm{HCV}$ infection in study populations is $21.34 \%$. On the other hand, Talebi et al., (2016) find that none of HCWs in Iran participants the HCV antibody is detected.

This can be attributed tothat most ofHCWs in the current study have received training courses in infection prevention and control, availability of disinfectants, personal protective equipment, infection prevention and control policy, and HBV vaccination at governmental hemodialysis units, and receiving HCWs HBV vaccination during work.

\section{Conclusion}

The results of the current study concluded that prevalence of both HBV and $\mathrm{HCV}$ among heath care workers at governmental hemodialysis units in Dakahlyagovernorate was very low; with the highest one for $\mathrm{HCV}$ than $\mathrm{HBV}$. Most of heath care workers exposed toneedle stick injuries, splashes of blood or its derivatives and they done the proper actions toward them. Health care workers did not perform regular virology investigationsof $\mathrm{HBV}$ and $\mathrm{HCV}$, while they regularly take complete vaccinations against $\mathrm{HBV}$.

Most of at governmental hemodialysis units in Dakahlyagovernoratehad a policy for infection prevention, and control concerning reporting incidence of needle stick injuries,splashes of biological fluids, and actions performed when those happened. Disinfectants and personal 
protective equipment were available for heath care workers. Finally most of health care workers took training on infection control policies.

\section{Recommendations}

On the light of the current study, the following recommendations are suggested:

- Regular screening for HBV and $\mathrm{HCV}$ infection status among HCWs especially in hemodialysis units should be performed.

- Continues and periodic training of healthcare workers on infection prevention, and control policies should be carried out.

- Provide HBV vaccine to HCWs especially newly hired;in addition to annual measuring antibody titer to know vaccine response to determine the need for booster dose.

\section{References}

AbdAlla, M. D. A., El-Dessouky, Y. M., Abdel-Hamid, M. R., \&Zain El-Deen, A. N. A. (2017).Prevalence of HCV Infection among Health Care Employee at Al Azhar University Hospitals in Cairo, Egypt. Journal of the Egyptian Society of Parasitology, 47(3), 459-466.

Aldohyan, M., Al-Rawashdeh, N., Sakr, F. M., Rahman, S., Alfarhan, A. I., \& Salam, M. (2019). The perceived effectiveness of MERS$\mathrm{CoV}$ educational programs and knowledge transfer among primary healthcare workers: a crosssectional survey. BMC infectious diseases, 19, 273.

Alrubaiee, G., Baharom, A., Shahar, H. K., Daud, S. M., \&Basaleem, H. O. (2017). Knowledge and practices of nurses regarding nosocomial infection control measures in private hospitals in
Sana'a City, Yemen. Safety in Health, 3, 1-6.

Amira, C. O., \&Awobusuyi, J. O. (2014). Needle-stick injury among health care workers in hemodialysis units in Nigeria: a multi-center study. Int $J$ Occup Environ Med (The IJOEM), 5(1 January), 228-1.

Awimero, C. E., Nelson, E. A., Yusuf, M., Olaosebikan, O. F., Adeboye, M. A. N., Adamu, U. G., ...\& Babalola, A. (2017). Knowledge, awareness and prevalence of viral hepatitis among health care workers (HCWs) of the Federal Medical Centre Bida, Nigeria.

Bernieh B. (2015). Viral hepatitis in hemodialysis: An update. Journal of translational internal medicine, 3(3), 93105.https://doi.org/10.1515/jtim2015-0018

Brooks, S. K., Greenberg, N., Wessely, S., \& Rubin, G. J. (2020). Factors affecting healthcare workers' compliance with social and behavioural infection control measures during emerging infectious disease outbreaks: Rapid evidence review. medRxiv.

Butsashvili, M., Kamkamidze, G., Kajaia, M., Morse, D. L., Triner, W., Dehovitz, J., \& McNutt, L. A. (2012).Occupational exposure to body fluids among health care workers in Georgia.Occupational medicine, 62(8), 620-626.

Chuc, N. T. K., Hoa, N. Q., Lan, P. T., Thoa, N. T. M., Riggi, E., Tamhankar, A. J., \&Lundborg, C. S. (2018). Knowledge and selfreported practices of infection control among various occupational groups in a rural and 
an urban hospital in

Vietnam.Scientific reports, 8, 1-6.

Çiçek-Şentürk, G., Tekin, A., Gürbüz, Y., Tütüncü, E. E., Sevinç, G., Kuzi, S., ...\&Şencan, İ. (2019). Retrospective investigation of 9 years of data on needlestick and sharps injuries: Effect of a hospital infection control committee American journal of infection control, 47(2), 186-190.

De Schryver, A., Lambaerts, T., Lammertyn, N., François, G., Bulterys, S., \&Godderis, L. (2020). European survey of hepatitis $B$ vaccination policies for healthcare workers: An updated overview. Vaccine, 38(11), 24662472.

Desta, M., Ayenew, T., Sitotaw, N., Tegegne, N., Dires, M., \&Getie, M. (2018).Knowledge, practice and associated factors of infection prevention among healthcare workers in Debre Markos referral hospital, Northwest Ethiopia. BMC health services research, 18, 465. https://doi.org/10.1186/s12913018-3277-5

Deuffic-Burban, S., DelarocqueAstagneau, E., Abiteboul, D., Bouvet, E., \&Yazdanpanah, Y. (2011). Blood-borne viruses in health care workers: prevention and management. Journal of Clinical Virology, 52, 4-10.

El-Melligy, D. M., Saad-Hussein, A., \& Khalil, S. A. (2016). Occupational exposure to hepatitis infection among Egyptian healthcare workers and hepatitis B vaccination. Journal of The Arab Society for Medical Research, 11, 14.

Elzouki, A. N., Elgamay, S. M., Zorgani, A., \&Elahmer, O.
(2014).Hepatitis B and C status among health care workers in the five main hospitals in eastern Libya. Journal of infection and public health, 7(6), 534-541.

Fabrizi, F., \&Messa, P. (2015). Transmission of hepatitis $\mathrm{C}$ virus in dialysis units: a systematic review of reports on outbreaks. The International journal of artificial organs, 38(9), 471-480.

Foda, N. M. T., Elshaer, N. S. M., \& Sultan, Y. H. M. (2018). Safe injection procedures, injection practices, and needlestick injuries among health care workers in operating rooms. Alexandria Journal of Medicine, 54, 85-92.

Gaziano, T. A., Abrahams-Gessel, S., Denman, C. A., Montano, C. M., Khanam, M., Puoane, T., \& Levitt, N. S. (2015). An assessment of community health workers' ability to screen for cardiovascular disease risk with a simple, noninvasive risk assessment instrument in Bangladesh, Guatemala, Mexico, and South Africa: an observational study. The Lancet Global Health, 3(9), e556-e563.

Hebo, H. J., Gemeda, D. H., \&Abdusemed, K. A. (2019). Hepatitis B and C viral infection: prevalence, knowledge, attitude, practice, and occupational exposure among healthcare workers of Jimma University Medical Center, southwest Ethiopia. The Scientific World Journal, vol.2019, 1-11.

Himmelreich, H., Rabenau, H. F., Rindermann, M., Stephan, C., Bickel, M., Marzi, I., \& Wicker, S. (2013). The management of 
needlestick

injuries. DeutschesArzteblatt

international, 110(5),

$61-$

67.https://doi.org/10.3238/arztebl. 2013.0061

Iliyasu, G., Dayyab, F. M., Habib, Z. G., Tiamiyu, A. B., Abubakar, S., Mijinyawa, M. S., \& Habib, A. G. (2016). Knowledge and practices of infection control among healthcare workers in a Tertiary Referral Center in North-Western Nigeria. Annals of African medicine, 15, 34.

Jefferies, M., Rauff, B., Rashid, H., Lam, T., \& Rafiq, S. (2018). Update on global epidemiology of viral hepatitis and preventive strategies. World journal of clinical cases, 6(13), 589-599.

Kapadia, S. N., \& Marks, K. M. (2018). Hepatitis C management simplification from test to cure: a framework for primary care providers. Clinical therapeutics, 40(8), 1234-1245.

Khamis, S. S., Yasin, Y. S., Omara, M. M., \& Saleh, N. E. (2018). Safety measures in Dakhlia hemodialysis units. Menoufia Medical Journal, 31(2), 429.

Khamis, S., Koura, M., Ragheb, A., \&Ezz-El-Din, A. (2018). Assessment of safety measures in hemodialysis units in Menoufia. Menoufia Medical Journal, 31(2), 443.

Kulbok, P.A., Thatcher, E., Park, E., Meszaros, P.S. (May 31, 2012) "Evolving Public Health Nursing Roles: Focus on Community Participatory Health Promotion and Prevention" OJIN: The Online Journal of Issues in Nursing Vol. 17, No. 2, Manuscript 1.
Litwin, M. How to Measure Survey Reliability and Validity. Thousand Oaks, CA: Sage Publications; 1995

Mahajan, S., \& Gupta, E. (2019).Needle Stick Injury in Healthcare Workers. Indian Journal of Health Sciences and Care, 6(2), 80-91.

Mahfouz, A. A., Al-Zaydani, I. A., Abdelaziz, A. O., El-Gamal, M. N., \&Assiri, A. M. (2014).Changes in hand hygiene compliance after a multimodal intervention among health-care workers from intensive care units in Southwestern Saudi Arabia. Journal of epidemiology and global health, 4(4), 315-321.

Maruish ME, editor. User's Manual for the SF-36v2 Health Survey. 3rd ed. Lincoln, RI: Quality Metric Incorporated; 2011.

Miller MJ. Graduate Research Methods. Available from: http:// www.michaeljmillerphd.com/res5 $00 \ldots /$ reliability and validity. pdf. [Last accessed on 2015 Oct 10].

Ottino, M. C., Argentero, A., Argentero, P. A., Garzaro, G., \&Zotti, C. M. (2019). Needlestick prevention devices: data from hospital surveillance in Piedmont, Italy - comprehensive analysis on needlestick injuries between healthcare workers after the introduction of safety devices. BMJ open, 9(11).

Polit DF, Beck CT. The content validity index: Are you sure you know what's being reported? Critique and recommendations. Res Nurs Health 2006;29:489-97.

Raad, I. I., Chaftari, A. M., Torres, H. A., Ayoub, E. M., Narouz, L. I., Bartek, J., \&Hachem, R. (2018). 
Challenge of hepatitis $\mathrm{C}$ in Egypt and hepatitis B in Mauritania. World journal of hepatology, 10(9), 549-557. doi:10.4254/wjh.v10.i9.549

Samargandy, S. A., Bahlas, R. S., Aldigs, E. K., Alawi, M. A., AlAbdullah, N. A., \&Madani, T. A. (2016). Epidemiology and clinical consequences of occupational exposure to blood and other body fluids in a university hospital in Saudi Arabia. Saudi medical journal, 37(7), 783790.https://doi.org/10.15537/smj.2 016.7.14261.

Sani, N. M., Bitrus, I., Sarki, A. M., \& Mujahid, N. S. (2018).Seroprevalence of Hepatitis $\mathrm{B}$ and $\mathrm{C}$ among Healthcare Workers in Dutse Metropolis Jigawa State, Nigeria. bioRxiv, 327940.

Schillie, S., Vellozzi, C., Reingold, A., Harris, A., Haber, P., Ward, J. W., \& Nelson, N. P. (2018). Prevention of Hepatitis B Virus Infection in the United States: Recommendations of the Advisory Committee on Immunization Practices. MMWR. Recommendations and reports : Morbidity and mortality weekly report. Recommendations and reports, $67, \quad 1-31$. doi:10.15585/mmwr.rr6701a1

Shahdadi, H., \&Rahnama, M. (2018). Experience of Nurses in Hemodialysis Care: A Phenomenological Study. Journal of clinical medicine, 7(2), 30. https://doi.org/10.3390/jcm702003 $\underline{0}$

Shao, E. R., Mboya, I. B., Gunda, D. W., Ruhangisa, F. G., Temu, E. M., Nkwama, M. L., ... \&Maro, V.
P. (2018). Seroprevalence of hepatitis $B$ virus infection and associated factors among healthcare workers in northern Tanzania. BMC infectious diseases, 18, 474.

Talebi, T. M., Rismantab, S., Khaleghi, S., Keyvani, H., Barati, M., \&Soltani, S. (2016).

Seroprevalence of HCV Infection among Health Care Workers in Two Teaching Hospitals, Tehran, Iran. INFECTION EPIDEMIOLOGY AND MICROBIOLOGY

Volume 2, Number 3; Page(s) $28-30$

Tanhope, M., \& Lancaster, J. (2011). Public health nursing: Population-centered care in the community (8th ed.). St. Louis, MO: Mosby

Tavakol M, Dennick R. Making sense of Cronbach's alpha. Int J Med Educ 2011;2:53-5.

Tavoschi, L., Mason, L., Petriti, U., Bunge, E., Veldhuijzen, I., \&Duffell, E. (2019).Hepatitis B and $\mathrm{C}$ among healthcare workers and patient groups at increased risk of iatrogenic transmission in the European Union/European Economic Area. The Journal of hospital infection, 102(4), 359368.

Tufon, K. A., Meriki, H. D., Kwenti, T. E., Tony, N. J., Malika, E., Bolimo, A. F., Kouanou, Y. S., Nkuo-Akenji, T., \&Anong, D. N. (2019). HBV Transmission Risk Assessment in Healthcare Workers, Household and Sexual Contacts of HBV Infected Patients in the Southwest Region of Cameroon. Oman medical journal, 34(4), 313- 
321.https://doi.org/10.5001/omj.20 19.62

Voide, C., Darling, K. E., KenfakFoguena, A., Erard, V., Cavassini, M., \&Lazor-Blanchet, C. (2012).Underreporting

of needlestick and sharps injuries among healthcare workers in a Swiss University Hospital. Swiss medical weekly, 142(w13523), 17.

Westermann, C., Peters, C., Lisiak, B., Lamberti, M., \&Nienhaus, A. (2015). The prevalence of hepatitis C among healthcare workers: a systematic review and metaanalysis. Occupational and environmental medicine,72(12), 880-888.

Yasin, J., Fisseha, R., Mekonnen, F., \&Yirdaw, K. (2019). Occupational exposure to blood and body fluids and associated factors among health care workers at the University of Gondar Hospital, Northwest Ethiopia. Environmental Health and Preventive Medicine, 24, 18.

Yassin, S. I., SOLIMAN, M., HODA, I., OSMAN, N. A., \& SALMA, A. (2018).Assessment of Infection Control Knowledge and Practices among Hemodialysis Nursing Staff in Kasr Al-Ainy Hospitals. The Medical Journal of Cairo University, 86(June), 16491656.

Yuan, Q., Wang, F., Zheng, H., Zhang, G., Miao, N., Sun, X., ...\& Cui, F. (2019). Hepatitis B vaccination coverage among health care workers in China. PloS one, 14(5), e0216598. 